\title{
La materialización de las políticas públicas: un acercamiento al poder judicial como actor clave de las políticas The Materialization of Public Policies:
}

\section{An Approach to the Judiciary as a Key Actor in Policies}

\author{
José Ignacio Torres Justiniani \\ Universidad Michoacana de San Nicolás de Hidalgo / \\ Universidad Virtual del Estado de Guanajuato UVEG \\ ORCID ID 0000-0002-3216-219X \\ ignacio.justiniani@umich.mx
}

\section{Cita recomendada:}

Torres Justiniani, J. I. (2021). La materialización de las políticas públicas: un acercamiento al poder judicial como actor clave de las políticas. Eunomía. Revista en Cultura de la Legalidad, 21, pp. 97-123.

doi: https://doi.org/10.20318/eunomia.2021.6341

Recibido / received: 20/04/2020

Aceptado / accepted: 20/04/2021

\begin{abstract}
Resumen
El presente artículo tiene como objetivo revelar la importancia que juega el poder judicial en las políticas públicas. A partir del análisis de las facultades del sistema judicial, así como de los elementos fundamentales de la disciplina de las políticas se propone una matriz de cotejo, la cual permite, a partir del análisis de casos, determinar cómo afecta el sistema judicial a la disciplina, así como a su ciclo. Para ello, en la primera parte de este trabajo se establecen las facultades exclusivas del poder judicial y su relación con las políticas, en la segunda parte, se analizan los aspectos primordiales de estas, inmediatamente después, se comienza con el estudio de casos, para lo cual, se ha construido una matriz de cotejo que permitirá determinar las etapas afectadas por las resoluciones judiciales. Finalmente se ofrecen unas breves conclusiones.
\end{abstract}

\section{Palabras clave}

Políticas públicas, sistema judicial, análisis de caso, intervención judicial, matriz de cotejo.

\section{Abstract}

This article aims to reveal the importance of the judiciary in public policy. Based on the analysis of the faculties of the judiciary, as well of the fundamental elements of the discipline of public policies, a comparison matrix is proposed, which allows, based on the analysis of cases, to determine how the judicial system affects the discipline, as well as its cycle. To do this, in the first part of this work the exclusive faculties of the judicial power and its relationship with policies 
are established, in the second part, their fundamental aspects of are analyzed, immediately after, the case study begins, for wich a comparison matrix has been constructed that will allow determine the stages affected by the judicial resolutions. Finally, some brief conclusions are offered.

\title{
Keywords
}

Public policies, judicial system, case analysis, judicial intervention, comparison Matrix.

\begin{abstract}
SUMARIO. 1. Introducción. 2. Sistema judicial y políticas públicas: una relación inevitable. 3 . Efectos de las resoluciones judiciales en las políticas públicas. 4. Intervención judicial en las políticas públicas: análisis de casos emblemáticos. 4.1 Metodología: matriz de cotejo para el análisis de la intervención judicial en las políticas públicas 4.2 Caso Sudáfrica sobre acceso a la vivienda. 4.3. Argentina: caso Mendoza sobre contaminación ambiental. 4.4. Amparo en Revisión 1359/2015. 4.5. Juicio de Amparo 707/2016: acceso a la salud para personas vulnerables. 5. Conclusiones.
\end{abstract}

\section{Introducción}

En los últimos años algunos casos emblemáticos han permitido a los académicos, así como a los especialistas en los temas jurídicos y de políticas públicas, adentrarse en la importancia de la participación judicial en la disciplina de políticas. Algunos de estos han propiciado, a través de diversos canales (conferencias, talleres, cursos, documentales, etc.) que sea casi imposible ignorar al sistema judicial como un actor clave en la materialización de las políticas. Por lo anterior, en el presente trabajo analizaré los efectos de las decisiones del sistema judicial en las políticas a partir de estudios de caso. Para ello, comenzaré primero por explicar los efectos de las decisiones del sistema judicial en la disciplina, lo que me permitirá ofrecer algunas respuestas a las siguientes interrogantes ¿Cuál es la relación entre políticas públicas y sistema judicial? ¿Cómo puede participar el sistema judicial en estas? Clarificadas las interrogantes anteriores, procederé al análisis de casos emblemáticos, señalando en cada uno de ellos sus características principales.

El primer caso es sobre derecho a la vivienda en Sudáfrica. Inmediatamente después se analiza el caso Matanza Riachuelo de 2008 sobre medio ambiente en Argentina. Posteriormente, se analizan dos casos en México, el primero es el Amparo en Revisión 1359/2015 de 2017, promovido por la asociación civil Artículo 19, amparo que resulta de suma importancia en la relación entre poder judicial y poder legislativo y, el segundo, es un caso local, de Morelia, Michoacán, el amparo 707/2016 de 2016, el cual permitirá adentrarnos a los cambios que parecen augurar una mayor influencia del sistema judicial en las políticas, al menos en lo que respecta a su materialización individual. Finalmente, se ofrecen algunas conclusiones sobre los posibles efectos de las decisiones judiciales tanto en las políticas públicas en general, así como en las diversas etapas o ciclo de políticas, señalando entre otras cosas, en cuáles de ellas es más probable encontrar sus efectos más significativos.

\section{Sistema judicial y políticas públicas: una relación inevitable}

El poder ejecutivo y el poder legislativo representan quizá la cara más visible en la puesta en marcha de los programas y proyectos, pero ello no significa que dicha puesta en marcha sea solitaria e inconexa al entorno político, jurídico y social. Si bien, no es el tema central de este trabajo, baste decir que el poder legislativo incide de manera importante en las políticas de diversas maneras, entre ellas podemos 
destacar la facultad de auditoría de los recursos, aprobación del presupuesto, evaluación de las políticas (comparecencias, informes de gobierno, órganos especializados en fiscalización) y, por supuesto, aquellas que se derivan de su facultad legislativa (Gris y Ramírez, 2019).

La relación entre el sistema judicial y las políticas públicas no resulta para algunos del todo evidente, y en algunos casos, se ha llegado a considerar que el poder judicial no debería intervenir en las políticas. Al respecto, el juez emérito de Estados Unidos, Ruggero J. Aldisert, expone que: «Algunos críticos argumentan desde una postura institucional, argumentando que articular políticas para el bien común es tarea del estado y las legislaturas nacionales y no así de las judicaturas federales o estatales» (Aldisert, 2099, p. 230), posición que él mismo rechaza, argumentando que la labor del juez va más allá de la mera resolución de conflictos, señalando que al resolverlos también hace política pública (Aldisert, 2009). En el mismo sentido, el profesor del Oriel College de Oxford, Daniel Butt (Butt, 2006, p. 5), considera que el poder judicial ha ganado en los últimos años cierta preminencia, ya sea como alternativa al poder ejecutivo o como plataforma para ingresar diversos intereses a la agenda gubernamental, en todo caso, es innegable que en los últimos años el poder judicial se ha constituido como una alternativa o herramienta que permite intervenir en los asuntos públicos, sobre todo en aquellos en los que los políticos se mantienen alejados por ser electoralmente no redituables (Butt, 2006, p. 5). Para conocer la relación entre políticas públicas y sistema judicial, es necesario abordar al menos, dos dimensiones, la primera es la relativa a las facultades exclusivas del poder judicial, sobre todo en lo que atañe al control constitucional y, la segunda, es la reciente ola de constitucionalismo global, la cual explica en gran medida la enorme importancia del sistema judicial en las políticas actuales.

En cuanto a las facultades exclusivas del poder judicial, debemos tener claro que la noción de separación de poderes asigna al poder judicial la función de «intérprete último de la Constitución y garante del orden constitucional» (Carmona, 2007 , p. 175). El sistema judicial se erige entonces como el único autorizado para interpretar lo contenido en la Constitución, es decir, es el único que puede establecer qué significa y cómo debe entenderse la ley, a quiénes afecta, cuáles son sus alcances, etc., estas facultades actualmente la ostentan los llamados tribunales constitucionales ${ }^{1}$, tribunales que tienen la función de:

interpretar la legalidad ordinaria de conformidad con la Constitución y con arreglo a su sentido lógico y actual, de tal suerte que, mediante su doctrina jurisprudencial uniforme, se dote de seguridad a todo el ordenamiento, garantizando, en último término, el principio constitucional de igualdad en la aplicación de la ley en todo el territorio nacional (Celeste, 2013, p. 78).

En pocas palabras, el poder judicial en cuanto a control constitucional, es el encargado de determinar los límites, alcances, interpretación, así como las diversas obligaciones y derechos de los distintos actores sujetos a la norma, ya sean públicos o privados. Por ende, el poder judicial deberá determinar, llegado el caso sometido a su consideración, la pertinencia o no de una política pública.

El análisis anterior nos permite comprender el impacto del segundo factor: el constitucionalismo global. En la actualidad vivimos en una era de constitucionalismo, la cual se caracteriza por una "autolimitación» de las sociedades a las reglas

\footnotetext{
1 Siguiendo a Fix-Zamudio, podemos definir a un tribunal constitucional como «aquellos que con independencia de su encuadramiento, dentro o fuera del poder judicial, deciden en última instancia sobre la interpretación definitiva de los principios, valores o normas fundamentales» (Fix-Zamudio, 2002, p. 212).
} 
establecidas en el ordenamiento constitucional (Miranda, 2018; Ackerman, 2006; Fernández, 1999; Cervantes, 1996), el cual, como ya analizamos, corresponde al poder judicial resguardar. Esto quiere decir que las sociedades actuales han decidido imponerse a sí mismas restricciones conforme a estructuras fundamentadas en textos constitucionales, así, los tribunales adquieren la tarea primordial de vigilar que las políticas se encuentren dentro de los márgenes del estado de derecho.

La ola de constitucionalismo global se intensifica a partir de la caída del sistema soviético. De 188 países miembros de las Naciones Unidas en ese momento, el $56 \%$ de estos realizó reformas a sus constituciones en el periodo que va de 1989 a 1999, adoptando el $70 \%$ de estos, constituciones totalmente nuevas (Cepeda, Montealegre y Alexei, 2007, p. 10). Como resultado de esta oleada constitucionalista, para el año 2000, al menos 92 países habían integrado en su sistema constitucional cartas de derechos fundamentales, de los cuales, al menos 36 países han creado un modelo de control constitucional centralizado en una corte o tribunal constitucional (Cepeda, Montealegre y Alexei, 2007, p. 11). En consecuencia, un gran número de sistemas democráticos se rigen por un modelo de control constitucional, vigilancia que le compete a un tribunal constitucional, esto quiere decir que dentro de los márgenes jurídicos del país de que se trate:

El tribunal constitucional es considerado como su supremo intérprete, no porque la Constitución así lo declare, sino porque su configuración dentro del ordenamiento jurídico y las competencias que se le asignan determinan que, aunque no sea el único que interprete y controle la Constitución, es el último (Miranda, 2018, p. 93).

Estos dos factores, el constitucionalismo global y la facultad exclusiva del órgano judicial como garante del orden constitucional, permiten comprender y entrelazar la relación simbiótica que guardan las políticas públicas y el sistema judicial, pues toda acción llevada a cabo por el gobierno debe respetar y estar acorde al sistema legal vigente:

(...) todo debe hacerse de acuerdo con la ley, que cuando se aplica a los poderes del gobierno significa que todo acto que afecte los derechos, deberes o libertades legales de cualquier persona, se debe demostrar que dicha acción posee una estricta procedencia legal. Las personas afectadas siempre pueden recurrir a los tribunales de justicia, y si la procedencia legal resulta no ser adecuada, la corte invalidará el acto, después de lo cual, puede ser ignorado o descartado sin riesgos. El significado secundario del estado de derecho...es que el gobierno debe conducirse dentro de un marco de normas y principios reconocidos que restringen el poder discrecional. Las disputas sobre la ley deben ser resueltas por un poder judicial que sea independiente del gobierno (Hill y Hupe, 2002, p. 23).

Se hace evidente entonces, que la relación entre políticas y sistema judicial esta enmarcada en el estado de derecho, es decir, si entendemos mínimamente por estado derecho la sujeción de todos (tanto gobernantes y gobernados) a las leyes ${ }^{2}$, entonces es inevitable e incluso condenable y atacable judicialmente, una política que no encuadre con el sistema legal. Por lo tanto, todo hacedor de política pública debe estar al tanto de las normas jurídicas al momento de realizar la política, ya que de no hacerlo la política en cuestión podrá ser atacada judicialmente, de ahí que sea de

\footnotetext{
2 Tomo como referencia la definición de la Organización de las Naciones Unidas: «un principio de gobernanza en el que todas las personas, instituciones y entidades, públicas y privadas, incluido el propio Estado, están sometidas a leyes que se promulgan públicamente, se hacen cumplir por igual y se aplican con independencia, además de ser compatibles con las normas y los principios internacionales de derechos humanos. Asimismo, exige que se adopten medidas para garantizar el respeto de los principios de primacía de la ley, igualdad ante la ley, separación de poderes, participación en la adopción de decisiones, legalidad, no arbitrariedad, y transparencia procesal y legal» (ONU, 2020).
} 
suma importancia que los actores de las políticas conozcan sobre el marco jurídico así como de los criterios más importantes por parte del sistema judicial, de no hacer lo anterior, la política corre el riesgo de ser descartada, lo que no solo implica un desperdicio de recursos, sino también puede llevar a la afectación de un sector amplio de la población.

Con lo anterior se ha dado respuesta a la primera pregunta sobre la relación entre políticas y sistema judicial, la cual adelanta y abona también a la respuesta de la segunda pregunta ¿Cómo puede participar el sistema judicial en las políticas?

\section{Efectos de las resoluciones judiciales en las políticas públicas}

Antes de analizar los diversos efectos de las resoluciones judiciales en las políticas públicas, debemos clarificar qué se entiende por políticas públicas. Como suele suceder en muchos conceptos que no tienen un significado único y aceptado, el concepto de políticas públicas es tan diverso como autores se consulte, por ello, he decidido adoptar la definición expuesta por Raúl Velásquez (2009), quien se ha dado a la tarea de realizar un análisis comparativo sobre las distintas definiciones, llegando a la siguiente conceptualización:

Política pública es un proceso integrador de decisiones, acciones, inacciones, acuerdos e instrumentos, adelantado por autoridades públicas con la participación eventual de los particulares, y encaminado a solucionar o prevenir una situación definida como problemática. La política pública hace parte de un ambiente determinado del cual se nutre y al cual pretende modificar o mantener (Velásquez, 2009, p. 156).

La utilidad de la definición de Velásquez radica sobre todo en su versatilidad, ya que expande lo que puede ser o no considerado como política pública, lo que permite considerar como política aquella que emana incluso de sistemas no democráticos y de negociaciones entre grupos cupulares o de presión para alcanzar intereses particulares, igualmente, el autor señala la pertinencia de la definición en tanto que permite reconocer que, en el ejercicio de las políticas, también esta inmerso un componente de corrupción y negligencia, los cuales deben reconocerse primero, para luego ser combatidos (Velásquez, 2009, p. 157).

Otra de las cuestiones importantes que se deben clarificar sobre las políticas públicas es lo referente a sus etapas o ciclo. Gran parte de las políticas siguen más o menos de forma uniforme, lo que la academia ha tenido a bien llamar ciclo de políticas. Este ciclo no es otra cosa que una serie de pasos o etapas para diseñar e implementar una política. Al igual que la definición, no existe un ciclo único y aceptado, es decir, existen tantas etapas como autores se consulte ${ }^{3}$. Es necesario mencionar aquí, que, en sus inicios, el estudio de las políticas contaba con etapas lineales o sucesivas, por lo que, al terminar una fase, se suponía que iniciaba la siguiente, dando como

\footnotetext{
${ }^{3}$ Por ejemplo, Lasswell, en su obra The Decision Process de 1956, identifica siete etapas: 1. Inteligencia, 2. Promoción, 3. Prescripción, 4. Invocación, 5. Aplicación, 6. Impacto y, 7. Evaluación (Parsons, 2007, p. 112). Por su parte, Eugene Bardach, identifica ocho pasos: 1. Definir el problema, 2. Recabar evidencia, 3. Construir las alternativas, 4. Seleccionar los criterios, 5. Proyección de resultados, 6. Confrontar los costos, 7. Decidir, 8. Contar la historia (Bardach, 2012). Hogwood y Gunn, en su obra Policy Analysis for the Real World de 1984, presentan nueve etapas: 1. Decidirse a decidir (búsqueda de problemáticas o definición de la agenda); 2. Decidir cómo decidir (filtración de problemáticas); 3. Decidir problemáticas; 4. Pronóstico; 5. Establecer objetivos y prioridades; 6. Analizar opciones; 7. Implementación, seguimiento y control de las políticas públicas; 8. Evaluación y Revisión; 9. Mantenimiento, sucesión y terminación de las políticas públicas (Parsons, 2007, p. 112-113). Luis Aguilar, por otro lado, señala siete pasos: 1. Formación de la agenda, 2. Definición del problema público, 3. Hechura o formulación de la política, 4. Decisión o selección entre opciones, 5. Comunicación política, 6. Implementación de la política y 7. Evaluación de la política (Aguilar, 2010, p. 34).
} 
resultado una especie de separación entre ellas. Esto cambió con la conceptualización de David Easton, quien consideraría a las etapas como un ciclo (Fischer, Miller y Sidney, 2007, p. 44).

Este acercamiento al análisis de políticas a partir del ciclo no esta exento de críticas. Autores como Michael Howlett, consideran que analizar las políticas públicas a partir del ciclo encubre la complejidad inherente en la creación de estas (Howlett, 2019), en la misma línea, Diane Stone, Simon Maxwell y Michael Keating, consideran que la concepción de ciclo «describe un modelo lineal de política que se mueve de una etapa a otra. En realidad, la creación de políticas es caótica» (Stone, Maxwell y Keating, 2001, p. 10). A pesar de estas críticas, autores como Sophia Everett, Thomas Dye y Thomas Birkland, han señalado las ventajas de contar con un ciclo de políticas, pues este permite analizar con mayor claridad las actividades al «interior» de la política, lo que facilita su estudio y análisis (Everett, 2003; Dye, 2013; Birkland, 2015). Teniendo en cuenta lo anterior, resulta de gran utilidad contar con etapas definidas, pues nos permite entre otras cosas, seccionar, localizar e identificar la influencia del sistema judicial en las políticas.

Al igual que con la definición expuesta con anterioridad, es necesario llegar a un punto común entre los diversos planteamientos existentes sobre el ciclo, por ello acudiré a la obra de Arias y Herrera (2012), quienes se han abocado a realizar un análisis de frecuencia y agrupamiento entre las distintas posturas en torno al ciclo de políticas públicas, analizando para ello a catorce autores especializados, llegando a cuatro etapas consistentes: definición del problema, diseño, implementación y seguimiento/evaluación (Arias y Herrera, 2012, p. 27).

Estas cuatro etapas nos permiten reducir al máximo el ciclo de las políticas, al menos en lo que se refiere a sus partes más «esenciales» y "frecuentes», sin embargo, dada la naturaleza de los efectos judiciales en las políticas, es necesario tomar en consideración otra etapa: la formación o ingreso a la agenda.

En contraste con Arias y Herrera, Mauricio Merino y Guillermo Cejudo adoptan un ciclo de cinco etapas, consistentes en: entrada en la agenda gubernamental, definición del problema, diseño de la política, implementación y evaluación (Merino y Cejudo, 2010; citados por Arellano y Blanco, 2013). Como podemos observar, la entrada en la agenda se presenta en estos autores como una fase individual. Al igual que estos, Aguilar contempla en sus siete pasos, a la formación de la agenda (Aguilar, 2010, p. 34), igualmente lo hacen: Birkland (2015), Dery (2000), May y Wildavsky (May y Wildavsky, 1978; citado por Subroto, 2011, p. 2), entre otros. Como podemos observar, estas propuestas integran una fase más, la de entrada en la agenda gubernamental.

Debido a la naturaleza de la interferencia del sistema judicial en las políticas, considero más apropiado un ciclo de cinco etapas, consistentes en: formación o ingreso a la agenda, definición del problema, diseño o formulación de la solución, implementación y evaluación o seguimiento. La elección de cinco y no cuatro etapas, se debe principalmente a uno de los efectos del sistema judicial, que como lo expondré más adelante, tiene una enorme influencia en la agenda tanto pública como gubernamental. Para comprender como influye el sistema judicial en las políticas, debemos primero revisar brevemente las características del ciclo.

La formación de la agenda gubernamental, parafraseando a Birkland (2015), es el proceso mediante el cual los problemas que se encuentran en el entorno social ganan la atención del gobierno, ello implica que existe una competición entre los diversos actores sociales para colocar su problema en la agenda, es decir, por ganar 
la atención del gobierno. La agenda se divide en dos partes fundamentales: la agenda pública y la gubernamental. La primera tiene que ver con los temas que se encuentran en la cotidianidad, es decir, los temas «candentes», "de moda» o que se consideran importantes por un amplio sector de la sociedad en un momento dado. Por otro lado, la agenda gubernamental es aquella en la cual el gobierno ya ha fijado su atención, y tiene la intensión de actuar sobre ellos dotándolos de recursos (Casar y Maldonado, 2010, citado por Arellano y Blanco, 2013, p. 41). Esta etapa es, como expondré más adelante y a partir del análisis de los casos seleccionados, una de las más afectadas por las decisiones judiciales.

La segunda fase, la definición del problema, posee, de acuerdo con David Dery, dos máximas que deben ser comprendidas:

La primera máxima de la definición del problema es reconocer que los problemas no existen "allá afuera», no son entidades abstractas en su propio derecho, sino construcciones analíticas. La segunda máxima, sugiere que las definiciones a problemas en el contexto de la práctica deben responder a los criterios de factibilidad y valor, o de progreso. Semejante análisis de políticas es definido como «crear y elaborar problemas que merece la pena resolver» (Dery, 2000, p. 40).

La definición del problema debe entenderse entonces, no como una definición holística y totalizadora de los problemas sociales, tal definición sería poco realista y casi imposible de resolver, por ello, se debe priorizar sobre los problemas que sea posible resolver con los recursos disponibles, esto lleva inevitablemente a que muchos de los hacedores de la política solo se enfoquen -para bien o para mal- en problemas locales o que no requieren mucho tiempo y recursos para ser solucionados, lo que abre un área de oportunidad para la intervención judicial en las políticas, ya que estas podrían forzar a los actores involucrados a considerar en su agenda temas más complejos, que por diversas razones (costo elevado en tiempo y recursos, cuestiones electorales, etc.) no son tomados en cuenta.

La tercera fase del ciclo, la formulación o diseño de la solución, puede entenderse como «el proceso mediante el cual las políticas son diseñadas, a través de análisis técnicos y procesos políticos, para alcanzar una meta en particular» (Birkland, 2015, p. 228). Por su parte, Arias y Herrera resaltan que en esta etapa se deben plantear:

objetivos claros y precisos; se identifica la población objetivo: afectados y beneficiarios; se analizan las alternativas con sus respectivos efectos, tanto positivos como negativos; se relacionan los costos y los beneficios de las alternativas; y se elige la mejor opción. En esta etapa, como en todas las demás, es importante la participación de los beneficiarios de la política, pues contribuyen a revisar los objetivos y los modos de llevarlos a cabo (Arias y Herrera, 2012, p. 57).

Lo anterior nos permite comprender una de las razones más importantes por las cuales debe participar el sistema judicial, ya que, si en una determinada política pública no se contempló a un sector de la población, o simplemente se aplicó esta de forma deficiente, el sistema judicial puede intervenir para corregir la aplicación. En pocas palabras, si una política fue construida excluyendo (intencionalmente o no) a un sector de la población, la intervención judicial puede ayudar a corregir dicho sesgo.

La cuarta fase, la implementación, puede definirse como «la capacidad de ejecutar, de llevar a cabo las acciones previstas para lograr los objetivos fijados en la etapa de diseño" (Arias y Herrera, 2012, p. 58). Para Parsons, la fase de implementación «es la continuación de la formulación de las políticas públicas por otros medios» (Parsons, 2007, p. 482). En esta etapa se hacen evidentes los errores 
o aciertos en las etapas anteriores, lo que supone que, si una política no ha contemplado los aspectos legales y jurídicos pertinentes, entonces esta no dará los resultados esperados, ya que muy probablemente, será atacada judicialmente, lo que puede poner en riesgo su éxito y continuidad. En esencia, la fase de implementación se refiere a la ejecución de la política, a su puesta en práctica, de ahí la importancia de acompañar esta ejecución con elementos que permitan, llegado el caso, a corregir cualquier desviación o error en que se haya podido incurrir en las etapas anteriores, se requiere entonces, de evaluación.

La quinta y última etapa del ciclo de políticas, la evaluación y seguimiento, que como dice Luis Aguilar «cierra y abre el ciclo o espiral de la política» (Aguilar, 2010, p. 51), se encuentra presente durante todo el proceso de la política. Rossi, Freeman y Lipsey, en su obra Evaluation a systematic approach, definen evaluación como: «el uso de procedimientos sociales de investigación para de forma sistemática investigar la efectividad de la intervención de los programas sociales» (Rossi, Freeman y Lipsey, 2004 , p. 4). Analizadas las etapas, conviene ahora mencionar, que la ventaja de analizar estas como ciclo, es que permite comprender con mayor facilidad la interacción entre los diversos mecanismos de creación de las políticas, así, no se trata de entender a las políticas solo como pasos a seguir, sino de comprender que existe una interacción entre las etapas, ello nos permite, por lo tanto, observar la relación que guardan entre sí, lo que hace evidente la importancia de evaluar cada una de ellas, pues si no se evalúa, se corre el riesgo de partir de supuestos erróneos, lo que afectaría a la larga toda la política. Por ejemplo, para definir el problema, se debe realizar un análisis del entorno (económico, social, político, etc.) lo que implica una evaluación "previa» de los elementos y su relación entre sí, con el objetivo de llegar una definición lo más acertada posible, y así en cada una de las etapas.

Establecidas a grandes rasgos las características principales de las políticas públicas y su ciclo, entremos al tema que nos interesa, sobre el cómo puede participar el sistema judicial en las políticas.

De acuerdo con las facultades exclusivas ya analizadas del sistema judicial, una resolución judicial puede tener cuatro efectos en una política pública: a) Vetar o reafirmar decisiones. El órgano judicial puede, a partir de la jurisprudencia, las normas y principios tanto nacionales como internacionales, vetar una determinada política, ya sea completamente o secciones de esta, así como reafirmarla; b) Actor proactivo. Esta influencia se refleja en la capacidad que tiene el juzgador para establecer y comunicar la forma en la que debe ser interpretada una determinada norma o principio, estableciendo para ello límites y requisitos específicos para el caso en concreto; c) Árbitro imparcial. El órgano judicial tiene la obligación de resolver las controversias sometidas a su consideración de manera imparcial, tomando en cuenta los postulados que garanticen una mayor protección a la persona; d) Representante de la sociedad. Este factor es resultado del punto anterior. Si bien es complicado que una persona pueda, como sujeto particular, lograr el ingreso de sus intereses a la agenda gubernamental, le es posible exigir la satisfacción de sus demandas a través del canal judicial, lo que, en circunstancias correctas, puede ser el parteaguas para un cambio en el tratamiento de un cierto derecho, en la lucha social de un cierto grupo vulnerable o, incluso, como el primer escalón a un cambio más profundo en el sistema político y jurídico de una localidad.

Como el lector ya se habrá podido dar cuenta, los puntos anteriores guardan una gran relación con los derechos humanos y, por ende, con las políticas públicas que tienen relación con estos. A partir de los casos analizados, es posible afirmar que los derechos humanos nos permiten observar los efectos más intensos de la intervención judicial en políticas. Lo anterior se puede explicar por dos razones, en 
primer lugar, los derechos humanos se materializan a partir de diversas políticas, las cuales muchas veces no están bien diseñadas o direccionadas, dejando a un sector de la población vulnerable, lo que puede ser atacado judicialmente. En segundo lugar, las políticas que se implementan en materia de derechos humanos suelen ser muy variadas, lo que da lugar a distintos niveles de afectación sobre los sujetos de la política, esto quiere decir, que debido a que los derechos humanos no son absolutos, corresponde al órgano judicial determinar los límites del derecho, es decir, a partir de un ejercicio de ponderación determinar límites y alcances, lo que sin lugar a dudas, puede afectar una determinada política. Para ejemplificar claramente los efectos ya mencionados, analizaré casos que permitirán observar claramente, como se presenta en la realidad la intervención judicial y cuál puede ser su alcance.

\section{Intervención judicial en las políticas públicas: análisis de casos emblemáticos}

Los casos que he seleccionado para evidenciar los efectos de la intervención judicial en las políticas públicas tienen relación directa con la materialización de derechos humanos, lo anterior es así porque considero que la intervención judicial es especialmente efectiva y visible en esta materia, además, cuando se trata de políticas públicas en materia de derechos humanos, estas no pueden esperar, ya que su afectación podría llevar a daños irreparables, lo que implica que la materialización de los derechos humanos, por su carácter urgente, sea un área en la cual las resoluciones judiciales manifiesten sus mayores efectos, al respecto, el ex presidente de la Corte Constitucional de Colombia, Juan Carlos Henao Pérez, establece que «se trata de asegurar que las políticas públicas se constituyan en una herramienta para la realización de los derechos humanos de las personas para las que se diseñan e implementan» (Henao, 2013, cita a Pérez, p. 74). Lo anterior explica por qué en la actualidad existe una tendencia creciente a nivel mundial en la participación de las cortes en el control de las políticas públicas (Quinche y Rivera, 2010, p. 122).

4.1. Metodología: matriz de cotejo para el análisis de la intervención judicial en las políticas públicas

El criterio para la elección de los casos a analizar, parte de los siguientes elementos, primero, que se trate de un país con un sistema judicial que contemple la existencia de un tribunal constitucional en los términos que ya hemos analizado, segundo, que contemple un marco de protección de derechos humanos garantizado en su ordenamiento jurídico, y, tercero, que la intervención en la política pública sea lo más evidente posible en los razonamientos judiciales, esto es, que se refiera expresamente a una política pública, de ahí que algunos de los casos seleccionados sean hoy en día considerados como paradigmáticos ${ }^{4} \mathrm{y}$, finalmente, que exista, al menos en el discurso, la intención por parte de las autoridades de resolver un problema público, es decir, que existieran políticas públicas (a punto de ser aplicadas o que ya están siendo aplicadas) diseñadas para dar solución al caso concreto. Con lo anterior en mente, procedo al análisis de los casos.

Antes de iniciar con el análisis de los efectos de las resoluciones judiciales sobre las políticas, es necesario introducir al lector a la matriz de cotejo que he diseñado, ello con el objetivo de responder a las interrogantes ¿Cuáles etapas son más afectadas y cuál puede ser el alcance de la intervención judicial en las políticas?

\footnotetext{
${ }^{4} \mathrm{Al}$ respecto, merece la pena revisar la Base de Datos de Jurisprudencia de la Red-DESC, que se enfoca en catalogar y suministrar una base de datos de casos emblemáticos sobre derechos humanos a nivel mundial, véase: https://www.escr-net.org/es/jurisprudencia
} 


\begin{tabular}{|c|c|c|c|}
\hline Etapas de política pública & Sí & No & Observaciones \\
\hline $\begin{array}{l}\text { 1. Ingreso o formación de la } \\
\text { agenda. } \\
\text { El órgano judicial actúa como } \\
\text { agente que permite el ingreso } \\
\text { de problemas en la agenda } \\
\text { gubernamental (representa a un } \\
\text { sujeto o sector minoritario o } \\
\text { vulnerable de la sociedad), al } \\
\text { requerirle a las autoridades que } \\
\text { actúen sobre un problema } \\
\text { sometido a su consideración. }\end{array}$ & & & \\
\hline $\begin{array}{l}\text { 2. Definición del problema. } \\
\text { El órgano judicial analiza en su } \\
\text { resolución diversos contextos } \\
\text { (históricos, culturales, jurídicos, } \\
\text { sociales, etc.) sentando en su } \\
\text { decisión un precedente, el cual } \\
\text { deberá ser tomado en cuenta } \\
\text { por los hacedores de la política } \\
\text { pública. }\end{array}$ & & & \\
\hline $\begin{array}{l}\text { 3. Elaboración o selección de la } \\
\text { solución. } \\
\text { El órgano judicial en su } \\
\text { resolución contrasta la política } \\
\text { pública en cuestión con la } \\
\text { normativa vigente, } \\
\text { determinando si se adecúa o } \\
\text { no, y en qué grado con esta } \\
\text { última. }\end{array}$ & & & \\
\hline $\begin{array}{l}\text { 4. Implementación. } \\
\text { El órgano judicial impone un } \\
\text { hacer o no hacer a los actores } \\
\text { involucrados con respecto a una } \\
\text { política pública identificada en la } \\
\text { resolución. }\end{array}$ & & & \\
\hline $\begin{array}{l}\text { 5.Evaluación y seguimiento. La } \\
\text { resolución judicial establece en } \\
\text { sus términos la entrega de } \\
\text { informes de seguimiento para } \\
\text { verificar el cumplimiento de su } \\
\text { decisión. }\end{array}$ & & & \\
\hline
\end{tabular}

Tabla 1. Matriz de cotejo. Fuente: elaboración propia.

Para cada una de las cinco etapas identificadas del ciclo de políticas he identificado cinco criterios, que, en caso de presentarse, señalarían una afectación sobre la etapa de política señalada. En el primer criterio, que tiene relación con la construcción de la agenda, considero esencial identificar dos cosas, la primera, que el órgano judicial se erija como representante de un sujeto o sector minoritario o vulnerable, lo que se puede observar al analizar quién y por qué promueve el recurso judicial, y, lo segundo, que en su decisión, el órgano judicial exija a las autoridades 
poner atención sobre una política pública. Lo anterior quedará claro cuando llenemos la matriz en cada uno de los casos.

En la segunda etapa, sobre la definición del problema, se debe poner atención a los precedentes judiciales que el órgano judicial pueda establecer, para lo cual, es fundamental tomar en cuenta el rango jerárquico del órgano judicial, ya que los alcances difieren. Por ejemplo, si se trata de un tribunal de primera instancia, su resolución todavía puede ser atacada en un tribunal superior, en cambio, si resuelve el máximo tribunal, lo que este determine se convertirá en un referente a ser tomado en cuenta por todos los actores en casos similares. De ahí que, si en la definición del problema los actores de políticas no realizan un análisis pormenorizado del tema, y no toman en cuenta los precedentes judiciales sobre el caso, la construcción que hagan del problema no será completa y corren el riesgo de ignorar avances en la materia que pudieras ser cruciales para el éxito de la política.

En la tercera etapa de elaboración o selección de la solución, es necesario identificar con atención el análisis realizado en la resolución, ello con el objetivo de determinar el contraste que realiza el órgano judicial entre la política pública y la normativa vigente. Por lo tanto, se debe advertir en la resolución la fundamentación y argumentación en donde se contrasta la política sometida a su consideración por un lado, y la normativa vigente por el otro, así, el órgano judicial podrá determinar qué elementos hacen falta por considerar o, incluso, si toda o alguna parte de la política es contraria o no con la normativa, lo que implica que el sistema judicial podrá, de acuerdo a sus facultades, vetar o reafirmar en todo o en parte a la política.

En la cuarta etapa, de implementación, la influencia del órgano judicial en las políticas se observa con mayor facilidad, ya que se busca que la resolución imponga un hacer o no hacer a los actores con respecto a la política sometida a su consideración, es decir, cualquier decisión que cambie o modifique en alguna forma la política en cuestión impacta directamente en la implementación.

En la quinta y última etapa, de evaluación, lo que se busca en la resolución es que esta imponga la entrega de informes de seguimiento, es decir, que los involucrados en la política pública entreguen información que mantenga al tanto del cumplimiento de la decisión al órgano judicial, lo que implica que este último evaluará y determinará si las autoridades están cumpliendo con lo que la resolución les ha mandatado.

Señalados los aspectos principales de la metodología para el análisis de las resoluciones a partir de la matriz de cotejo, procedo a analizar el primer caso paradigmático, el caso Sudáfrica.

\subsection{Caso Sudáfrica sobre acceso a la vivienda}

El primer caso emblemático que analizaré es: The Government of the Republic of South Africa and others vs. Grootboom, Irene and Others (en adelante caso Sudáfrica) del 4 de octubre de 2000. En el año de 1998, un grupo de personas en extrema pobreza (390 adultos y 510 niños) fueron desalojados de un asentamiento informal en Wallacedene, que se encuentra en los suburbios de Ciudad del Cabo, por lo que se mudaron a un asentamiento cercano, un centro de deportes, en donde construyeron viviendas precarias de plástico y otros materiales, sobra decir que no contaban con servicios básicos, como agua, electricidad o drenaje.

Para el año de 1999, ante un panorama de abandono y sin una solución en el horizonte por parte de las autoridades, los afectados interpusieron una acción legal 
con fundamento en los artículos 26 -sobre acceso a la vivienda- y 28 -protección de la niñez- de la Constitución sudafricana. En una primera instancia, el tribunal aceptó la acción legal y ordenó «al gobierno proveer refugio a las familias con niños, estableciendo que debía reunir ciertas condiciones mínimas como letrinas y suministro de agua» (Abramovich y Courtis, 2001, p. 71). Decisión que el gobierno nacional y de la Provincia de Cabo apeló ante la Corte Constitucional de Sudáfrica.

Lo que me gustaría resaltar en este caso, es que los demandantes buscaron por medios legales acceder a una vivienda, la misma resolución judicial así lo establece en sus antecedentes, menciona, por ejemplo, que las personas habían aplicado para un subsidio de vivienda, pero que al pasar siete años sin respuesta decidieron que no tenían más alternativa que invadir otro terreno (Corte Constitucional de Sudáfrica, 4 de octubre del 2000, p. 7). Esto es importante, ya que se menciona claramente la existencia de una política pública para resolver el problema en materia habitacional, pero a consideración de la Corte, esta no había dado los resultados esperados.

La Corte, a lo largo del estudio del caso, fue enfática en señalar que el derecho a la vivienda debía facilitar la materialización del derecho de forma progresiva, así mismo, reconoce que «los contornos y el contenido de las medidas a adoptar son ante todo un asunto que compete al legislativo y al ejecutivo» (Corte Constitucional de Sudáfrica, 4 de octubre del 2000, pp. 32-33). Esto resulta de enorme importancia para el presente trabajo, pues la Corte deja claro que su decisión no pretende sustituir la labor del legislativo y el ejecutivo en cuanto al diseño de las políticas, de ahí que la Corte se aboque en determinar, a partir de un análisis de razonabilidad, si las medidas tomadas por las autoridades demandadas cumplían con los estándares establecidos en la Constitución:

Es necesario reconocer que el Estado cuenta con un amplio espectro de posibles medidas que podría adoptar para cumplir su obligación. Muchas de esas medidas podrían satisfacer el estándar de razonabilidad. Una vez que se demuestra que la medida adoptada satisface el estándar, la obligación del Estado se tiene por cumplida (Abramovich y Courtis, 2001, p. 73).

En lo que se refiere a que el Estado debe tomar medidas razonables ya sean legislativas o de otra índole, la Corte señala que las medidas legislativas por sí mismas nos son suficientes para cumplir con lo que establece la Constitución, y determina que:

El Estado esta obligado a actuar para alcanzar el resultado deseado, y las medidas legislativas deberán ser invariablemente apoyadas por políticas bien dirigidas, así como programas implementados por el ejecutivo. Estas políticas y programas deben ser razonables tanto en su concepción como implementación. La formulación de un programa es solo la primera etapa para cumplir con las obligaciones del Estado. EI programa debe ser también razonablemente implementado. De otra manera un programa razonable que no sea implementado razonablemente no constituirá cumplimiento con las obligaciones del Estado (Corte Constitucional de Sudáfrica, 4 de octubre del 2000, p. 33).

Con lo expuesto en el párrafo anterior, la Corte delinea claramente lo que será su participación en las políticas públicas. Lo importante entonces, no es crear una ley o un programa, sino que éste dé resultados, así, la Corte se erige como el órgano encargado de determinar si una política cumple o no, con lo que dispone la Constitución. 
Siguiendo con su análisis, la Corte establece que cualquier programa diseñado o implementado o por implementar por parte del ejecutivo o legislativo, deberá contemplar los aspectos sociales, culturales, históricos, etc., propios del lugar (en este caso el apartheid), así como contemplar medidas de mediano y largo plazo para satisfacer las necesidades de la población objetivo. De no cumplir el Estado con lo anterior, entonces las medidas no serán consideradas como razonables y apropiadas de acuerdo con el marco legal (Corte Constitucional de Sudáfrica, 4 de octubre del 2000, p. 34).

\section{Por lo tanto, la Corte llega a la siguiente resolución:}

(a) La sección 26(2) de la Constitución requiere que el Estado diseñe e implemente de acuerdo con sus recursos disponibles, un programa comprensivo y coordinado para realizar progresivamente el derecho al acceso a la vivienda adecuada. (b) El programa debe incluir medidas razonables tales como, pero no necesariamente limitadas a, aquellas contempladas en el Programa Acelerado de Asentamiento Territorial, a proveer alivio a las personas que no tienen acceso a la tierra, que no tienen techo sobre sus cabezas, así como aquellos que están viviendo en condiciones intolerables o en situación de crisis. (c) A la fecha de publicación de esta aplicación, el programa de vivienda estatal en el área de Consejo Metropolitano del Cabo se ha quedado corto en satisfacer los requerimientos del párrafo (b), pues ha fallado en hacer una provisión razonable dentro de sus recursos disponibles para las personas en el área Metropolitana del Cabo sin acceso a la tierra, sin techo sobre sus cabezas, así como aquellos que están viviendo en condiciones intolerables o en situación de crisis (Corte Constitucional de Sudáfrica, 4 de octubre del 2000, pp. 67-68)

Como se hace evidente a partir de la resolución sudafricana, la Corte ordena a las autoridades crear una política pública -párrafo (a) -, así como garantizar que esta satisfaga las necesidades de la población más vulnerable -párrafo (b) - y, además, dictamina que lo hecho hasta el momento de la resolución no ha sido suficiente -párrafo (c) - .

Una vez explicados cada uno de los criterios de la tabla de cotejo, así como los pormenores del caso, procedo a capturar en la tabla la información obtenida del Caso Sudáfrica, para quedar como sigue:

\begin{tabular}{|c|c|c|c|}
\hline Etapas de política pública & Sí & No & Observaciones \\
\hline $\begin{array}{l}\text { 1. Ingreso o formación de la } \\
\text { agenda. } \\
\text { El órgano judicial actúa como } \\
\text { agente que permite el ingreso } \\
\text { de problemas en la agenda } \\
\text { gubernamental (representa a } \\
\text { un sujeto o sector minoritario o } \\
\text { vulnerable de la sociedad), al } \\
\text { requerirle a las autoridades } \\
\text { que actúen sobre un problema } \\
\text { sometido a su consideración. }\end{array}$ & Sí & & $\begin{array}{l}\text { En el caso Sudáfrica, las personas que } \\
\text { solicitan la protección judicial } \\
\text { pertenecen a un grupo vulnerable, el } \\
\text { cual, como la misma autoridad lo } \\
\text { menciona se encuentran "sin acceso a } \\
\text { la tierra, sin techo sobre sus cabezas, } \\
\text { así como aquellos que están viviendo en } \\
\text { condiciones intolerables o en situación } \\
\text { de crisis" (Corte Constitucional de } \\
\text { Sudáfrica, } 4 \text { de octubre del 2000, p. 68) }\end{array}$ \\
\hline $\begin{array}{l}\text { 2. Definición del problema. } \\
\text { El órgano judicial analiza en su } \\
\text { resolución diversos contextos } \\
\text { (históricos, culturales, jurídicos, } \\
\text { sociales, etc.) sentando en su } \\
\text { decisión un precedente, el cual } \\
\text { deberá ser tomado en cuenta }\end{array}$ & Sí & & $\begin{array}{l}\text { A lo largo de la resolución, el órgano } \\
\text { judicial hace referencia a las } \\
\text { condiciones culturales, históricas, } \\
\text { sociales y jurídicas que engloban a las } \\
\text { políticas de vivienda en Sudáfrica, sobre } \\
\text { todo en lo que respecta al apartheid, la } \\
\text { segregación de sectores de la sociedad }\end{array}$ \\
\hline
\end{tabular}




\begin{tabular}{|c|c|c|}
\hline $\begin{array}{l}\text { por los hacedores de la política } \\
\text { pública. }\end{array}$ & & $\begin{array}{l}\text { y la poca o nula atención a la población } \\
\text { vulnerable en los suburbios. }\end{array}$ \\
\hline $\begin{array}{l}\text { 3. Elaboración o selección de } \\
\text { la solución. } \\
\text { El órgano judicial en su } \\
\text { resolución contrasta la política } \\
\text { pública en cuestión con la } \\
\text { normativa vigente, } \\
\text { determinando si se adecúa o } \\
\text { no, y en qué grado con esta } \\
\text { última. }\end{array}$ & Sí & $\begin{array}{l}\text { Como se analizó, la Corte es enfática en } \\
\text { señalar que, respecto a lo contemplado } \\
\text { en su Constitución, principalmente en } \\
\text { los artículos } 26 \text { y } 28, \text { y lo que las } \\
\text { políticas establecen como desarrollo } \\
\text { habitacional, las políticas fallan en no } \\
\text { diseñar y contemplar una alternativa } \\
\text { "mínima" para las personas vulnerables. }\end{array}$ \\
\hline $\begin{array}{l}\text { 4. Implementación. } \\
\text { El órgano judicial impone un } \\
\text { hacer o no hacer a los actores } \\
\text { involucrados con respecto a } \\
\text { una política pública identificada } \\
\text { en la resolución. }\end{array}$ & Sí & $\begin{array}{l}\text { La Corte impone un hacer con respecto } \\
\text { a la política de vivienda, lo que queda } \\
\text { manifiesto en los párrafos (a) y (b) de la } \\
\text { resolución. }\end{array}$ \\
\hline $\begin{array}{l}\text { 5.Evaluación y seguimiento. La } \\
\text { resolución judicial establece en } \\
\text { sus términos la entrega de } \\
\text { informes de seguimiento para } \\
\text { verificar el cumplimiento de su } \\
\text { decisión. }\end{array}$ & Sí & $\begin{array}{l}\text { En su resolución, la Corte nombra a un } \\
\text { "vigilante" externo para que dé cuenta } \\
\text { del cumplimiento de lo dispuesto en la } \\
\text { resolución, este vigilante es la Comisión } \\
\text { de Derechos Humanos o el Defensor del } \\
\text { Pueblo. }\end{array}$ \\
\hline
\end{tabular}

Tabla 2. Matriz de cotejo. Fuente: elaboración propia.

Llenada la matriz de cotejo, se hace evidente que la resolución del caso Sudáfrica afecta a las políticas públicas de forma total, es decir, afecta a todas las etapas de política pública, lo que hace de esta resolución un ejemplo de los alcances de una decisión judicial en las políticas.

\subsection{Argentina: caso Mendoza sobre contaminación ambiental}

Al igual que con el caso Sudáfrica, el caso «Mendoza Beatriz Silva y otros contra Estado Nacional y otros s/ daños y perjuicios» (en adelante caso Mendoza) sobre contaminación ambiental en Argentina, es un caso paradigmático, por lo que puedo anticipar desde ahora que impactará en todas las etapas de política pública.

El caso Mendoza es un ejemplo en todos los sentidos de una resolución que tiene un enorme efecto en las políticas públicas. Al igual que el caso Sudáfrica, en el cual se contempla la existencia de contralores para vigilar el cumplimiento de la resolución (en ese caso la Comisión de Derechos Humanos o el Defensor del Pueblo), en el caso Mendoza, la autoridad nombró vigilantes en el proceso (cuerpo colegiado compuesto por cinco instituciones no gubernamentales coordinadas por el Defensor del Pueblo) e incluso fue más allá, al contemplar fechas de vencimiento, multas a las autoridades, y en esencia, sanciones bien establecidas en caso de que no se cumpla con lo dispuesto en la política pública por ellos diseñada.

El camino al caso Mendoza comienza en el año 2004, en el que un grupo de personas interpusieron una demanda ante la Corte Suprema Argentina en contra de entidades estatales (Estado Nacional, la Provincia de Buenos Aires y la Ciudad Autónoma de Buenos Aires) así como contra cuarenta y cuatro empresas privadas, con el objetivo de obtener indemnización por daños y perjuicios a consecuencia de la contaminación del río Matanza-Riachuelo, solicitando la restauración del medio ambiente. 
La resolución judicial del caso Mendoza sienta un precedente de tremenda importancia para las políticas públicas de Argentina, así como para el estudio de la intervención judicial en las políticas. Para delinear los mayores aportes de la resolución, destacaré los puntos que considero más importantes, para después, utilizando la matriz de cotejo, señalar qué etapas del ciclo de políticas se ven más afectas y por qué.

La Corte Suprema desde un primer momento ya interviene en las políticas, pues requiere a las empresas demandadas, la entrega de informes que establezcan, qué arrojan al río, qué tratamiento les dan a los desechos, entre otras cosas. Por otro lado, a las autoridades (Estado Nacional, Ciudad Autónoma de Buenos Aires y CoFeMa) se les ordenó entregar:

un plan integrado que contemple un ordenamiento ambiental del territorio, el control sobre las actividades antrópicas, el estudio sobre el impacto ambiental de las empresas demandadas, un programa de educación ambiental y un programa de información ambiental" (Sentencia M. 1569.XL de 8 de julio, pp. 1-2).

En pocas palabras, la autoridad judicial ordena la creación de una política pública por parte de las autoridades. Sin duda, una de las partes que indican el grado de involucramiento que tendrá la autoridad judicial en la política de saneamiento se puede observar en el punto «6» de la sentencia, en el cual, la Corte, una vez que ha escuchado el informe por parte de las autoridades sobre su programa de saneamiento, interroga a las autoridades sobre dicho plan. Esto es monumental, pues tenemos a una autoridad judicial, la que tradicionalmente no se involucra en las políticas públicas, haciendo preguntas sobre una política, su viabilidad y elementos (Sentencia M. 1569.XL de 8 de julio, punto 6, p. 6).

Continuando con su análisis sobre la política pública para sanear el río (programa de saneamiento), la Corte ordenó a las autoridades involucradas en la política presentar los avances de la misma, lo interesante aquí viene en el apartado numero "8", que transcribo a continuación:

Que el 23 de febrero de 2007 el Tribunal, tras subrayar que carecía de los elementos cognoscitivos necesarios para dictar el pronunciamiento que en aquel grado de desarrollo del proceso correspondía tener, ejerciendo nuevamente sus facultades instructorias y ordenatorias, ordenó la intervención de la Universidad de Buenos Aires. Ello, a fin de que con la actuación de sus profesionales con antecedentes y conocimientos necesarios y apropiados respecto de las diversas temáticas involucradas, procediesen a informar sobre la factibilidad del plan presentado en la causa por las autoridades estatales, según lo encomendado el 20 de junio de 2006 (fs. 1047) (Sentencia M. 1569.XL de 8 de julio, punto 8, p. 8).

Lo anterior refleja un nivel de entendimiento e involucramiento de enormes proporciones en cuanto a la política pública. La Corte, haciendo uso de sus facultades, reconoce que no cuenta con los elementos para determinar la viabilidad de la política, así, solicita a una instancia experta -Universidad de Buenos Aires-, el análisis de la política, con el fin de contar con elementos que le permitan resolver de forma adecuada.

En cuanto a las facultades de cada uno de los poderes, y con el ánimo de no intervenir en ámbitos que estén fuera de su competencia, el sistema judicial determina que:

El objeto decisorio se orienta hacia el futuro y fija los criterios generales para que se cumpla efectivamente con la finalidad indicada, pero respetando el modo en que se concreta, lo que corresponde al ámbito de discrecionalidad de la administración. De 
tal modo, el obligado al cumplimiento deberá perseguir los resultados y cumplir los mandatos descriptos en los objetivos que se enuncian en la presente, quedando dentro de sus facultades la determinación de los procedimientos para llevarlos a cabo (Sentencia M. 1569.XL de 8 de julio, punto 8, p. 14).

El párrafo anterior señala un aspecto que será definitorio en el futuro de la política pública, el que tiene que ver con la facultad exclusiva de las autoridades (excluyendo al poder judicial por supuesto) para diseñar e implementar el programa de saneamiento. En otras palabras, lo que el sistema judicial esta diciendo en el párrafo anterior, es que no es competencia de este determinar el cómo y con qué mecanismos se debe diseñar e implementar, así como tampoco lo es determinar los tiempos de la política, pero, que a partir del programa de saneamiento que las autoridades entreguen, dicho programa se convertirá en un elemento que permitirá al sistema judicial evaluar si las autoridades cumplen o no con lo que ellas mismas han establecido.

Quizá uno de los elementos más importantes para el tema de política pública expuestos por la resolución, sea el relativo a las sanciones previstas por la autoridad judicial en caso de incumplimiento de los objetivos en el programa de saneamiento. En su sentencia, la Corte determina que la política pública debe contener tres objetivos: 1) la mejora de la calidad de vida de los habitantes, 2) la recomposición del ambiente en la cuenca en todos sus componentes (agua, aire y suelos) y 3) la prevención de daños con suficiente y razonable grado de predicción (Sentencia M. 1569.XL de 8 de julio, I. Objetivos, p. 16). Como se puede observar, la Corte no dice a las autoridades cómo hacer y aplicar la política pública, solo establece lo que la política debe contener de acuerdo con los preceptos legales. Si bien la Corte no se involucra en el diseño e implementación de la política directamente, sí establece que, de no cumplir las autoridades con sus obligaciones, se harán acreedoras a multas:

Para medir el nivel de cumplimiento de esos objetivos la Autoridad de Cuenca deberá adoptar alguno de los sistemas internacionales de medición que se encuentran disponibles e informar al tribunal competente para la ejecución de esta sentencia en un plazo de 90 (noventa) días hábiles. El incumplimiento de la orden dentro del plazo establecido, importará la aplicación de una multa diaria a cargo del presidente de la Autoridad de Cuenca (Sentencia M. 1569.XL de 8 de julio, I) Objetivos, p. 16).

Por tal razón, considero que una de las etapas que se ven afectadas con mayor intensidad en esta resolución es la etapa de evaluación, ya que en este caso, la autoridad es muy específica al momento de imponer fechas límite para la materialización del programa de saneamiento, entre las que destacan: organizar en un plazo de treinta días hábiles un sistema de información pública digital de libre acceso con toda la información del programa de saneamiento, realización de inspecciones a las empresas en un plazo no mayor de treinta días hábiles, solicitar a las empresas involucradas en el periodo señalado anteriormente, la entrega de un plan de tratamiento de residuos, la decisión en un plazo no mayor a sesenta días hábiles sobre la aprobación o no del plan presentado por las empresas por parte de la autoridad competente, la entrega de informes de seguimiento en los plazos convenidos, entre otros. Estos plazos se fortalecen mediante la imposición de multas al establecer la Corte que: «el incumplimiento de cualquiera de los plazos establecidos en cada etapa, importará la aplicación de una multa diaria a cargo del presidente de la Autoridad de Cuenca» (Sentencia M. 1569.XL de 8 de julio: Objetivos II y III, pp. 16-18). Finalmente, en su resolución la Corte garantiza la evaluación de la política al incluir mecanismos de participación ciudadana, así como la creación de un cuerpo colegiado para dar seguimiento al cumplimiento de la resolución: 
5.- Habilitar la participación ciudadana en el control del cumplimiento del Plan de Saneamiento y del programa fijado en el presente. 6.- Encomendar al Defensor del Pueblo de la Nación la coordinación de dicha participación, mediante la conformación de un cuerpo colegiado en el que participarán los representantes de las organizaciones no gubernamentales que intervienen en esta causa en condición de terceros interesados (Sentencia M. 1569.XL de 8 de julio, puntos 5 y 6 de la Resolución, pp. 27-28).

Expuesto lo anterior, solo queda capturar la información en la matriz de cotejo:

\begin{tabular}{|c|c|c|c|}
\hline Etapas de política pública & Sí & No & Observaciones \\
\hline $\begin{array}{l}\text { 1. Ingreso o formación de la } \\
\text { agenda. } \\
\text { El órgano judicial actúa como } \\
\text { agente que permite el ingreso } \\
\text { de problemas en la agenda } \\
\text { gubernamental (representa a } \\
\text { un sujeto o sector minoritario o } \\
\text { vulnerable de la sociedad), al } \\
\text { requerirle a las autoridades que } \\
\text { actúen sobre un problema } \\
\text { sometido a su consideración. }\end{array}$ & Sí & & $\begin{array}{l}\text { La Corte Suprema de Argentina atrae el } \\
\text { caso e impone a las autoridades la } \\
\text { obligación de atender los reclamos de la } \\
\text { población que vive en la cercanía de la } \\
\text { cuenca del río Matanza-Riachuelo } \\
\text { (Sentencia M.1569.XL de } 8 \text { de julio, pp. } \\
\text { 1-6) }\end{array}$ \\
\hline $\begin{array}{l}\text { 2. Definición del problema. } \\
\text { El órgano judicial analiza en su } \\
\text { resolución diversos contextos } \\
\text { (históricos, culturales, jurídicos, } \\
\text { sociales, etc.) sentando en su } \\
\text { decisión un precedente, el cual } \\
\text { deberá ser tomado en cuenta } \\
\text { por los hacedores de la política } \\
\text { pública. }\end{array}$ & Sí & & $\begin{array}{l}\text { La Corte Suprema ordena a las } \\
\text { autoridades demandadas la entrega de } \\
\text { informes y análisis medioambientales } \\
\text { que den cuenta de la situación de la } \\
\text { contaminación del río, así como de la } \\
\text { responsabilidad de las empresas } \\
\text { (Sentencia M.1569.XL de } 8 \text { de julio, pp. } \\
\text { 16-22) }\end{array}$ \\
\hline $\begin{array}{l}\text { 3. Elaboración o selección de la } \\
\text { solución. } \\
\text { El órgano judicial en su } \\
\text { resolución contrasta la política } \\
\text { pública en cuestión con la } \\
\text { normativa vigente, } \\
\text { determinando si se adecúa o } \\
\text { no, y en qué grado con esta } \\
\text { última. }\end{array}$ & Sí & & $\begin{array}{l}\text { La Corte realiza un extenso análisis y } \\
\text { contraste de lo expuesto por la política } \\
\text { pública presentada por las autoridades } \\
\text { (Programa de saneamiento) con la } \\
\text { normativa legal vigente (Sentencia } \\
\text { M.1569.XL de } 8 \text { de julio). }\end{array}$ \\
\hline $\begin{array}{l}\text { 4. Implementación. } \\
\text { El órgano judicial impone un } \\
\text { hacer o no hacer a los actores } \\
\text { involucrados con respecto a } \\
\text { una política pública identificada } \\
\text { en la resolución. }\end{array}$ & Sí & & $\begin{array}{l}\text { En su resolución, la Corte analiza impone } \\
\text { e las autoridades la obligación de realizar } \\
\text { una política pública (Sentencia } \\
\text { M.1569.XL de } 8 \text { de julio), consistente en } \\
\text { un programa de saneamiento, así mismo, } \\
\text { le impone la obligación de cumplir con } \\
\text { tres objetivos (p.16) que deberá contener } \\
\text { la política así como etapas sucesivas que } \\
\text { deberán cumplirse de acuerdo a cierto } \\
\text { orden dictado por la autoridad judicial. }\end{array}$ \\
\hline
\end{tabular}




\begin{tabular}{|l|l|l|}
\hline $\begin{array}{l}\text { 5.Evaluación y seguimiento. La } \\
\text { resolución judicial establece en } \\
\text { sus términos la entrega de } \\
\text { informes de seguimiento para } \\
\text { verificar el cumplimiento de su } \\
\text { decisión. }\end{array}$ & Sí & $\begin{array}{l}\text { La autoridad judicial crea un cuerpo } \\
\text { colegiado coordinado por el Defensor del } \\
\text { Pueblo en el cual participan cinco } \\
\text { organizaciones no gubernamentales, las } \\
\text { que evaluarán y le darán seguimiento a } \\
\text { lo expuesto en la resolución, además, } \\
\text { esta medida se refuerza con la } \\
\text { imposición de multas en caso de } \\
\text { incumplimiento (Sentencia M.1569.XL de } \\
8 \text { de julio), }\end{array}$ \\
\hline
\end{tabular}

Tabla 3. Matriz de cotejo. Fuente: elaboración propia.

Como podemos deducir, todas las etapas de política pública se ven afectadas: a) ingreso a la agenda, ya que la Corte llama a los demandados a poner atención en el tema y destinar recursos tanto humanos como materiales para el diseño de la política, que hasta ese momento tenían olvidada; b) Definición del problema, al requerir la creación de una política haciendo uso de análisis y estudios previos; c) elaboración de la solución, al imponerle requisitos y características que tendrá que cumplir el programa de saneamiento; d) implementación, al ordenar la creación de un programa de saneamiento con ciertas características, tanto de calidad como de tiempo y, finalmente, e) evaluación, al construir un cuerpo colegiado para vigilar el cumplimiento de la política así como el establecimiento de plazos de vencimiento y multas en caso de no cumplir con lo expuesto en el programa.

Analizados los casos de Sudáfrica y Argentina, expondré a continuación las implicaciones de la resolución 1359/2015 de México y sus efectos novedosos en la intervención del poder judicial en las políticas públicas.

\subsection{Amparo en Revisión 1359/2015}

El 23 de mayo de 2014, una asociación civil llamada Artículo 19, enfocada en la defensa de la libertad de expresión y acceso a la información, acudió a la justicia federal para reclamar la omisión por parte del poder legislativo -Cámara de Senadores y de Diputados- de expedir la ley reglamentaria relativa al uso y repartición del gasto en publicidad oficial, correspondiente al artículo 134 constitucional, en otras palabras, señalaban que el poder legislativo había incurrido en una violación a la Constitución (al vencer el periodo de tiempo fijado por los mismos legisladores para expedir una ley) exponiendo entre otros el siguiente argumento:

La omisión de la autoridad responsable viola la libertad de expresión, de prensa y de información, ya que la ausencia de un marco normativo reglamentario al artículo 134 de la Constitución permite un uso arbitrario y discrecional de la repartición de la publicidad oficial, generando con ello condiciones para que, por un lado, las autoridades utilicen los recursos públicos destinados a dicho fin para beneficiar a los medios de comunicación que son complacientes con aquéllas $\mathrm{y}$, por otro lado, castigar a los medios de comunicación y periodistas críticos, es decir, generando medios indirectos de censura que violentan las libertades de expresión, prensa e información (Amparo en Revisión 1359/2015, p. 5).

En su resolución, la Primera sala de la Suprema Corte de Justicia de la Nación se refiere a la omisión legislativa, que se enfoca en que el poder judicial no tiene competencia para expedir legislación cuando existe una omisión por parte del legislativo, pero en cambio, si tiene competencia para exigir a este legislar cuando la omisión trae como consecuencia una afectación a los derechos humanos. Así, la Primera Sala determina claramente que el legislativo es una autoridad responsable, y 
como tal, esta sometido a las leyes, estas últimas las cuales, le competen al poder judicial resguardar:

(...) esta Primera Sala estima que los tribunales de amparo tienen facultades constitucionales para ordenar la restitución de los derechos de los quejosos cuando éstos sean violados por una omisión legislativa absoluta. En un Estado constitucional de derecho todas las autoridades deben respetar la Constitución. Así, aun cuando el Poder Legislativo tenga una función de la máxima importancia dentro nuestro orden constitucional y ésta se le haya encomendado de manera exclusiva -aunque con cierta intervención del Poder Ejecutivo-, también se encuentra sometido a la Constitución. En consecuencia, en estos casos el Poder Legislativo no es libre para decidir no legislar. Cuando la Constitución establece un deber de legislar respecto de algún tema en específico a cargo del Poder Legislativo, el ejercicio de la facultad de legislar deja de ser discrecional y se convierte en una competencia de ejercicio obligatorio (Amparo en Revisión 1359/2015, p. 29).

Por lo anterior, la Primera Sala ordenó lo siguiente:

Por lo tanto, en este caso concreto esta Primera Sala concede el amparo para el efecto de que el Congreso de la Unión cumpla con la obligación establecida en el artículo tercero transitorio del decreto de la reforma constitucional de 10 de febrero de 2014 y, en consecuencia, proceda a emitir una ley que regule el párrafo octavo del artículo 134 de la Constitución antes de que finalice el segundo periodo ordinario de sesiones de este último año de la LXIII Legislatura, es decir, antes del 30 de abril de 2018 (Amparo en Revisión 1359/2015, p. 58).

La resolución de la Primera Sala abre la posibilidad para que el poder judicial «ejerza» completamente su poder como tribunal constitucional, y con ello, un papel preponderante en las políticas públicas. En esta resolución se puede observar cómo el poder judicial interviene en el diseño de las políticas públicas, si bien no de una forma tan contundente como en el caso argentino o sudafricano, sí lo hace al sentar un precedente en cuanto a la obligación, tanto del poder ejecutivo como legislativo, de acatar lo dispuesto en las normas, veamos cómo se ve en la matriz de cotejo.

\begin{tabular}{|c|c|c|c|}
\hline Etapas de política pública & Sí & No & Observaciones \\
\hline $\begin{array}{l}\text { 1. Ingreso o formación de la } \\
\text { agenda. } \\
\text { El órgano judicial actúa como } \\
\text { agente que permite el ingreso } \\
\text { de problemas en la agenda } \\
\text { gubernamental (representa a } \\
\text { un sujeto o sector minoritario o } \\
\text { vulnerable de la sociedad), al } \\
\text { requerirle a las autoridades que } \\
\text { actúen sobre un problema } \\
\text { sometido a su consideración. }\end{array}$ & & No & $\begin{array}{l}\text { En este caso, la resolución de la } \\
\text { autoridad judicial no afecta a la etapa, ya } \\
\text { que si bien fue un tema que se dejó de } \\
\text { lado (legislar), a final de cuentas este ya } \\
\text { se encontraba en la agenda } \\
\text { gubernamental (Amparo en Revisión } \\
\text { 1359/2015) }\end{array}$ \\
\hline $\begin{array}{l}\text { 2. Definición del problema. } \\
\text { El órgano judicial analiza en su } \\
\text { resolución diversos contextos } \\
\text { (históricos, culturales, jurídicos, } \\
\text { sociales, etc.) sentando en su } \\
\text { decisión un precedente, el cual } \\
\text { deberá ser tomado en cuenta } \\
\text { por los hacedores de la política } \\
\text { pública. }\end{array}$ & & No & $\begin{array}{l}\text { La autoridad judicial realiza un análisis } \\
\text { de antecedentes relativos a la } \\
\text { competencia del órgano judicial en la } \\
\text { decisión en materia de omisión } \\
\text { legislativa, pero no así de una política } \\
\text { pública (Amparo en Revisión 1359/2015) }\end{array}$ \\
\hline
\end{tabular}




\begin{tabular}{|l|l|l|}
\hline $\begin{array}{l}\text { 3. Elaboración o selección de la } \\
\text { solución. }\end{array}$ & No órgano judicial en su \\
$\begin{array}{l}\text { El osolución contrasta la política } \\
\text { pública en cuestión con la } \\
\text { normativa } \\
\text { determinando si se adecúa o } \\
\text { no, y en qué grado con esta } \\
\text { última. }\end{array}$ & $\begin{array}{l}\text { No este caso, al no existir aún una } \\
\text { política pública sino solo la orden de } \\
\text { crearla, el poder judicial no tiene política } \\
\text { pública para contrastar, salvo la ausencia } \\
\text { de esta y los efectos de este vacío en el } \\
\text { ordenamiento jurídico (Amparo en } \\
\text { Revisión 1359/2015, pp. 40-58). Esto es } \\
\text { así debido a que la solución (la política } \\
\text { pública representada en el reglamento } \\
\text { que no existe) ya ha sido seleccionada } \\
\text { por el legislativo, de ahí que el poder } \\
\text { judicial no tenga mayor injerencia. }\end{array}$ \\
\hline $\begin{array}{l}\text { f. Implementación. } \\
\text { El órgano judicial impone un } \\
\text { hacer o no hacer a los actores } \\
\text { involucrados con respecto a } \\
\text { una política pública identificada } \\
\text { en la resolución. }\end{array}$ & Sí & $\begin{array}{l}\text { Al establecer la obligación al poder } \\
\text { legislativo de legislar, en esencia, de } \\
\text { crear las reglas que regularán entre otras } \\
\text { cosas la repartición de tiempos de } \\
\text { publicidad oficial, el poder judicial esta } \\
\text { ordenando la creación de una política } \\
\text { pública (Amparo en Revisión 1359/2015, } \\
\text { p. 59) }\end{array}$ \\
\hline $\begin{array}{l}\text { 5.Evaluación y seguimiento. La } \\
\text { resolución judicial establece en } \\
\text { sus términos la entrega de } \\
\text { informes de seguimiento para } \\
\text { verificar el cumplimiento de su } \\
\text { decisión. }\end{array}$ & $\begin{array}{l}\text { La autoridad judicial no se involucra en } \\
\text { esta etapa, pues no contempla ningún } \\
\text { mecanismo de evaluación o seguimiento } \\
\text { Amparo en Revisión 1359/2015, p. 59) }\end{array}$ \\
\hline
\end{tabular}

Tabla 4. Matriz de cotejo. Fuente: elaboración propia.

Como se pudo observar, la resolución judicial analizada solo afecta a la etapa de implementación de la política, lo que refleja una afectación muy «débil» en las políticas públicas, sin embargo, hay que señalar que en los últimos años, en México ha habido un creciente interés por involucrar al sistema judicial en las políticas públicas, prueba de ello es la resolución que analizaremos a continuación.

\subsection{Juicio de Amparo 707/2016: acceso a la salud para personas vulnerables}

En julio del año 2016, una madre preocupada por la ausencia de atención médica especializada para su hija, así como la afectación que ello podría ocasionar para su salud, promovió un juicio de amparo (707/2016) para obtener la atención médica que las autoridades le negaban. Se trata de un caso local de Morelia, Michoacán, en el que una autoridad local -Juzgado Séptimo de Distrito- emitió una resolución para amparar a una menor de edad que padece síndrome de down, así como de un padecimiento llamado pectus carinatum.

Es importante resaltar en este caso, que los medicamentos disponibles para tratamientos incluidos en la política de salud (representada en el catálogo de servicios de salud del Seguro Popular) no contemplaba la afección de pectus carinatum, por lo que la niña no podía acceder al tratamiento más adecuado para su afección, en este caso un pectoral que debía ser importado de otro país con un costo de más de cuatro mil dólares (Amparo 707/2016, p. 45). Como se puede anticipar, solicitar a los actores tradicionales de la política pública (poder legislativo y poder ejecutivo) que legislen o actualicen el catálogo de salud, o que cubran el costo de la afección, aún y cuando no se encuentre prevista, no es viable, pues hay que recordar que al tratarse de un padecimiento que puede poner en riesgo la vida de una persona, acudir a las instancias antes mencionadas consumiría mucho tiempo y esfuerzo, lo que pone en riesgo la vida de la niña. 
Al resolver el caso, el juzgado determinó que la autoridad había sido omisa en cumplir con su responsabilidad en materia de acceso a la salud, al determinar que se comete una violación cuando el «Estado Mexicano no adopte medidas apropiadas de carácter legislativo, administrativo, presupuestario, judicial o de otra índole, para dar plena efectividad al derecho indicado» (Amparo 707/2016, p. 51). Más adelante en la resolución, la autoridad va perfilando lo que será su decisión al determinar que el Estado tiene la obligación de brindar el tratamiento, aún y cuando no se encuentre dentro del catálogo:

(...) de tal manera que, si el tratamiento que aqueja a la quejosa denominado pectus carinatum no se encuentra contemplado en el catálogo universal contemplado en el programa denominado "Seguro Popular»; es evidente que es obligación del Estado procurar el otorgamiento del tratamiento que garantice que el derecho a la salud de la quejosa sea ejercido sin discriminación alguna y adoptar las medidas para su plena realización, que deben ser deliberadas y concretas, es decir, avanzar lo más expedita y eficazmente posible hacia su plena realización (Amparo 707/2016, p. 80).

Ya en la parte final de la resolución la autoridad judicial establece, al responder a la interrogante: ¿Qué tipo de órdenes se podrían establecer para cumplir con el ejercicio del contenido esencial del derecho? Lo que será su aportación más importante al caso:

a) El inmediato otorgamiento del tratamiento para el padecimiento denominado pectus carinatum, consistente en la colocación del compresor dinámico, que funciona como un sistema ortésico para remodelar el tórax de manera paulatina y basado en una medición de la elasticidad del tórax; y, b) La posterior inclusión en el Catálogo Universal de Servicios de Salud (CAUSES), en el que se enlistan los servicios médicos-quirúrgicos, farmacéuticos y hospitalarios a los que tienen derecho y que podrán solicitar en los centros de salud y hospitales cubiertos, los beneficiarios del Seguro Popular, el padecimiento que aqueja a la peticionaria de amparo, denominado pectus carinatum (Amparo 707/2016, p. 90).

Aquí, el objetivo del juzgador se centra en dos cosas, la primera es garantizar el acceso a la salud y, la segunda, que su decisión tenga efectos vinculantes y pueda lograr así integrar la afección al catálogo de salud. Lo anterior sin duda tendría efectos en la política pública de salud, pues implicaría modificar el catálogo, así como asignar los recursos tanto materiales como humanos para garantizar el tratamiento de dicho padecimiento, sin embargo, casi inmediatamente, la autoridad judicial que resuelve el caso, reconoce que no podrá lograr lo dispuesto en el segundo inciso, al respecto señala: "Sin embargo, respecto de la orden precisada en el inciso b), es pertinente señalar que este juzgador de amparo, en el caso, no se encuentra en posibilidades de ordenar la inclusión del referido padecimiento al Catálogo Universal de Servicios de Salud" (Amparo 707/2016, p. 91). Lo anterior es así, ya que la autoridad judicial reconoce en primer lugar, que no tiene la jerarquía constitucional para sentar precedentes que permitan modificar o anular una normativa, facultad que solo posee el máximo tribunal del país y, en segundo lugar, que quizá no es ámbito de su competencia. 
Teniendo en cuenta lo anterior, la matriz de cotejo quedaría como sigue.

\begin{tabular}{|c|c|c|c|}
\hline Etapas de política pública & Sí & No & Observaciones \\
\hline $\begin{array}{l}\text { 1. Ingreso o formación de la } \\
\text { agenda. } \\
\text { El órgano judicial actúa como } \\
\text { agente que permite el ingreso } \\
\text { de problemas en la agenda } \\
\text { gubernamental (representa a } \\
\text { un sujeto o sector minoritario o } \\
\text { vulnerable de la sociedad), al } \\
\text { requerirle a las autoridades } \\
\text { que actúen sobre un problema } \\
\text { sometido a su consideración. }\end{array}$ & Sí & & $\begin{array}{l}\text { Aunque el órgano judicial reconoce no } \\
\text { tener facultades para modificar el } \\
\text { catálogo de salud, la resolución en sí, } \\
\text { a pesar de tener solo efectos } \\
\text { individuales, sienta un precedente } \\
\text { para aquellos que tengan un } \\
\text { padecimiento similar, lo que implica } \\
\text { que este derecho puede ser } \\
\text { garantizado por la vía judicial del } \\
\text { mismo modo que lo fue en este caso } \\
\text { (Amparo } 707 / 2016, \text { p. 91) }\end{array}$ \\
\hline $\begin{array}{l}\text { 2. Definición del problema. } \\
\text { El órgano judicial analiza en } \\
\text { su resolución diversos } \\
\text { contextos (históricos, } \\
\text { culturales, jurídicos, sociales, } \\
\text { etc.) sentando en su decisión } \\
\text { un precedente, el cual deberá } \\
\text { ser tomado en cuenta por los } \\
\text { hacedores de la política } \\
\text { pública. }\end{array}$ & & No & $\begin{array}{l}\text { En este caso la autoridad no se refiere } \\
\text { en concreto a una política pública, sino } \\
\text { a una omisión de las autoridades para } \\
\text { garantizar el acceso a la salud, lo que } \\
\text { implica que la decisión se decante en } \\
\text { esos términos y no en una política } \\
\text { pública. }\end{array}$ \\
\hline $\begin{array}{l}\text { 3. Elaboración o selección de } \\
\text { la solución. } \\
\text { El órgano judicial en su } \\
\text { resolución contrasta la política } \\
\text { pública en cuestión con la } \\
\text { normativa vigente, } \\
\text { determinando si se adecúa o } \\
\text { no, y en qué grado con esta } \\
\text { última. }\end{array}$ & & No & $\begin{array}{l}\text { Como se mencionaba en la etapa } \\
\text { anterior, la decisión se ocupa de los } \\
\text { pormenores del acceso al derecho a la } \\
\text { salud, y no así de una política pública } \\
\text { concreta. }\end{array}$ \\
\hline $\begin{array}{l}\text { 4. Implementación. } \\
\text { El órgano judicial impone un } \\
\text { hacer o no hacer a los actores } \\
\text { involucrados con respecto a } \\
\text { una política pública } \\
\text { identificada en la resolución. }\end{array}$ & & No & $\begin{array}{l}\text { Si la decisión hubiera sido emitida por } \\
\text { el máximo tribunal del país, sin duda la } \\
\text { respuesta sería sí, sin embargo, al } \\
\text { tratarse de un juzgado } \\
\text { jerárquicamente inferior en la escala } \\
\text { judicial, su decisión no tiene la } \\
\text { capacidad de modificar el catálogo de } \\
\text { salud, lo que implica que los efectos en } \\
\text { la implementación sean muy limitados, } \\
\text { lo que no motiva a la autoridad a } \\
\text { modificar por su cuenta el catálogo, así } \\
\text { como tampoco ofrecer el tratamiento } \\
\text { sino es por intermedio de una orden } \\
\text { judicial. }\end{array}$ \\
\hline $\begin{array}{l}\text { 5. Evaluación y seguimiento. } \\
\text { La resolución judicial } \\
\text { establece en sus términos la } \\
\text { entrega de informes de } \\
\text { seguimiento para verificar el } \\
\text { cumplimiento de su decisión. }\end{array}$ & & No & $\begin{array}{l}\text { La autoridad en su resolución no } \\
\text { contempla nada relacionado con la } \\
\text { etapa de evaluación. }\end{array}$ \\
\hline
\end{tabular}

Tabla 5. Matriz de cotejo. Fuente: elaboración propia. 


\section{Conclusiones}

A partir de los casos analizados, así como del análisis de las facultades exclusivas del poder judicial, y, de las características de las políticas públicas, se hace evidente que la intervención judicial puede resultar en muchos casos benéfica para la materialización de las políticas, al menos para aquellas que son de suma importancia para el bienestar social, es decir, aquellas que guardan relación con los derechos humanos.

La nueva ola de constitucionalismo global otorga al sistema judicial una importancia sin precedente en la materialización de las políticas públicas. Esto es así debido a que en los últimos años la falta de resultados por parte de los actores tradicionales de la política ha dado como consecuencia que las personas se acerquen cada vez, con mayor frecuencia, al sistema judicial para garantizar sus derechos.

Del análisis de los casos mencionados, es posible señalar (al menos en aquellos sistemas jurídicos que guardan similitudes como las expuestas anteriormente) que el sistema judicial, partiendo del control constitucional, puede tener facultades para imponer la creación de una política pública, para ordenar qué contenido mínimo debe tener un programa o proyecto, para evaluar y dar seguimiento $y$, en suma, para determinar si una política cumple o no con lo que establece el sistema normativo. Los efectos de las decisiones del sistema judicial en las políticas en los casos sudafricano y argentino fueron totales, es decir, afectaron a todo el ciclo de políticas públicas, esto podría explicarse porque en dichos países existe un mayor desarrollo y entendimiento de la participación judicial en la política, esto es así, quizá debido al acercamiento que estos países han tenido con los regímenes autoritarios, en el caso sudafricano, su herencia de racismo y segregación y, en el argentino, su pasado con los golpes militares y las dictaduras, lo que explica en parte, por qué el sistema judicial se ha visto como una alternativa viable para equilibrar el juego de poderes y garantizar una mejor distribución de los beneficios de las políticas. En el escenario mexicano, es evidente que el poder judicial aún no despliega todo su potencial e influencia en las políticas públicas, así lo sugieren los casos analizados de este país, sin embargo, existe una disposición por parte del sistema judicial de influir con mayor intensidad y cotidianidad en las políticas.

La relación entre políticas públicas y sistema judicial se explica a partir del marco jurídico, del estado de derecho y de los márgenes constitucionales, así mismo, la participación del poder judicial en las políticas se visualiza con mayor facilidad en cuatro aspectos, consistentes en vetar o reafirmar decisiones, como actor proactivo que delimita los alcances de interpretación de las normas o principios, como árbitro imparcial que permite una mayor protección a la persona, y, como representante de la sociedad, al permitir que ciertos temas puedan ser ingresados a la agenda.

Cada uno de los casos analizados nos ha brindado ejemplos del alcance que puede llegar a tener la participación del sistema judicial en las políticas. En el caso sudafricano, la Corte determina contenidos mínimos que deberá observar el programa de vivienda, así como la población objetivo que deberá ser atendida de forma prioritaria. Al tratarse de un tema sensible con raíces en el apartheid, la Corte se convierte en la vía o el puente entre los desfavorecidos, los olvidados y aquellos en las posiciones de poder. En el caso argentino, los efectos son aún más específicos, pues la Corte Suprema argentina participa en la construcción de la política y en su evaluación, señalando además los actores (cuerpo colegiado) que evaluaran los avances del programa así como multas en caso de que no se cumpla con los tiempos de la política. Lo que nos enseñan ambos casos, es el potencial enorme que tiene el poder judicial para participar en las políticas, dicha participación puede permitir que 
aquellos que han sido olvidados o puestos de lado encuentren una vía para ver materializados sus derechos.

A partir de los casos analizados, considero que es factible señalar que existen etapas que se pueden ver más afectadas que otras por las decisiones judiciales. Las que considero más sensibles a la intervención judicial son las etapas de ingreso y formación de la agenda y la de implementación. La primera debido a las facultades y atributos de los órganos jurisdiccionales, sobre todo en lo que se refiere a los tribunales constitucionales (defensa del orden constitucional, defensa de derechos humanos etc.), pues «deciden en última instancia sobre la interpretación definitiva de los principios, valores o normas fundamentales» (Fix-Zamudio, 2002, p. 212). Lo que significa que cualquier demanda que puedan tener sectores vulnerables respecto a la poca o nula atención por parte de las autoridades, traducida esta a una política, podrá ser corregida (al menos en parte) por la vía judicial. En cuanto a la implementación, los efectos de la resolución en las políticas son más evidentes, ya que el juzgador puede determinar modificar la política implementada, redireccionarla, o incluso eliminarla. Por ejemplo, en el caso local de Morelia, Michoacán, se puede observar cómo una de las pretensiones del juzgador era modificar el catálogo de salud, sin embargo, este debe reconocer que no cuenta con la jerarquía judicial necesaria, pero, de no haber sido así, habría impactado en la implementación de la política.

Le sigue en afectación las etapas de definición del problema y construcción de la solución. Considero que la participación del sistema judicial en las políticas, sobre todo en lo que atañe a las etapas antes mencionadas, debe venir acompañada de una amplia comunicación y cooperación entre el legislativo y ejecutivo. La participación judicial, si bien, puede ser en muchos casos -como los analizados- muy benéfica para lograr la materialización de las políticas, esta debe desarrollarse en un ambiente que permita a los tres poderes -legislativo, ejecutivo y judicial- funcionar mejor en el respectivo ámbito de su competencia, pues no debemos olvidar que una de las principales razones para un aumento en la participación judicial en las políticas viene de un vacío que han dejado el legislativo y ejecutivo en cuanto a su capacidad para garantizar políticas públicas eficaces, lo que a largo plazo, no puede ser sustituido por un activismo judicial en las políticas, por ello, la participación de este último, si bien considero es fundamental para encauzar políticas -implementación-, e incluir a sectores vulnerables -formación de la agenda-, no puede por sí misma llenar el vacío dejado por la ausencia de políticas adecuadas.

En cuanto a la construcción de la solución, el caso de Sudáfrica, y el de Argentina, nos permiten observar una intervención del sistema judicial más desarrollada, en la cual la concepción de la realidad, así como la forma en la que se debe interpretar el contexto del problema es definido en gran parte por la interpretación que de él hace el sistema judicial, señalando los puntos esenciales que deberá tomar en consideración el hacedor de la política.

Finalmente, considero que, a partir de los casos analizados, la etapa de evaluación es la que se ve afectada con menos frecuencia, esto se debe a que influir en la evaluación de las políticas, implica para el poder judicial el más elevado grado de intervención posible. Intervenir en la evaluación requiere construir un esquema de seguimiento que compromete en el mediano y largo plazo al sistema judicial en la política, lo que lo hace más compleja su participación, así mismo, implica superar obstáculos en cuanto a la percepción de la separación de poderes, la cual en muchas ocasiones asume que el poder judicial no debe participar en las políticas.

En conclusión, la participación de sistema judicial en las políticas públicas es un campo aún en construcción. Su influencia representa un enorme potencial para 
lograr la materialización de esta disciplina, por lo que debe ser tomado en cuenta en los estudios sobre la materia. Para ello, es necesario que los miembros de los tres poderes estén dispuestos a participar más activamente y cooperar entre sí, y con ello buscar garantizar una mayor eficiencia y aplicación de las políticas. Así mismo, creo necesario recalcar que las conclusiones expuestas en este trabajo representan una visión construida a partir de casos específicos, así como de sistemas jurídicos más o menos equiparables entre sí, por lo que no pretendo generalizar los resultados a todos los escenarios ni a todos los casos, sin embargo, considero que este trabajo puede servir para orientar a aquellos que estén interesados en analizar los posibles alcances y límites de la intervención judicial en las políticas. Por otro lado, vale la pena mencionar que una posible conclusión adicional a las expuestas con anterioridad y que merecería un futuro análisis y estudio, es el relativo al aparente incremento del activismo judicial en países con mayores niveles de desigualdad y corrupción, lo que en apariencia podría explicarse por la falta de resultados de los poderes legislativo y ejecutivo, en todo caso, hay aquí un fértil campo de estudio aún no explorado que podría arrojar mayor luz sobre los alcances y límites de la participación judicial en las políticas públicas.

\section{Bibliografía}

Abramovich, V. y Courtis, C. (2001). La justiciabilidad del derecho a la vivienda en la reciente jurisprudencia sudafricana. Jueces para la Democracia, 40, pp. 71-75.

Abramovich, V. y Courtis, C. (1997). Hacia la exigibilidad de los derechos económicos, sociales y culturales. Estándares internacionales y criterios de aplicación ante los tribunales locales. En M. Abregú (ed.), La aplicación de los tratados sobre derechos humanos por los tribunales locales (pp. 283-350). Buenos Aires, Argentina: Del Puerto.

Aguilar, L. (2010). Política pública. Ciudad de México, México: Siglo XXI Editores.

Aldisert, R. (2009). Judicial declaration of public policy. The Journal of Appellate Practice and Process, 10(2), pp. 229-245.

Aldunate, E., y Córdoba, J. (2011). Formulación de programas con la metodología de marco lógico. Serie de Manuales, 68 (LCL/L.3317-P), Comisión Económica para América Latina y el Caribe (CEPAL). Recuperado de: https://www.cepal.org/ilpes/publicaciones/xml/0/43220/SM N68 Formulacion pr og metodologia ML.pdf

Arellano, D. y Blanco, F. (2013). Políticas públicas y democracia. Ciudad de México, México: Instituto Federal Electoral.

Arias, D. y Herrera, H. (2012). Entre políticas gubernamentales y políticas públicas. Análisis del ciclo de las políticas de desarrollo del gobierno del Estado de Michoacán, México, 2003-2010. Ciudad de México, México: Instituto Nacional de Administración Pública.

Bardach, E. (2012). A practical guide for policy analysis: the eightfold path to more effective problem solving. Los Angeles, United States of America: Sage.

Birkland, T. (2015). An introduction to the policy process: theories, concepts, and models of public policy making. New York, United States of America: Routledge.

Butt, D. (2006). The courts and social policy in the United States. The Foundation of Law, Justice and Society. Recuperado de: https://www.fljs.org/sites/default/files/migrated/publications/Butt\%2520report.pdf

Carmona, U. (2007). La división de poderes y la función jurisdiccional. Revista Latinoamericana de Derecho, IV(7-8), pp. 175-211. 
Celeste, C. (2013). La función de los tribunales constitucionales y la eficacia de sus sentencias a la espera de un caso emblemático. En A. Bonaveri, A. Buteler, A. Bestard, et. al., Estudios de derecho público (75-85). Buenos Aires, Argentina: Asociación de Docentes Facultad de Derecho y Ciencias Sociales Universidad de Buenos Aires.

Cepeda, M., Montealegre, E. y Alexei, J. (2007). Teoría constitucional y políticas públicas: bases críticas para una discusión. Bogotá, Colombia: Universidad Externado de Colombia.

Cervantes, L. (1996). Los tribunales constitucionales en el derecho comparado. Un estudio introductorio sobre sus antecedentes y situación jurídica actual. En A. Cancado, C. Moyer, y C. Zeledón. Estudios básicos de derechos humanos. (pp. 355-390). San José, Costa Rica: Instituto Interamericano de Derechos Humanos.

Constitutional Court of South Africa. (2021). Constitución de Sudáfrica de 1996. Recuperado de: https://www.concourt.org.za/index.php/constitution/the-text

Dery, D. (2000). Agenda setting and problem definition. Policy Studies, 21(1), pp. 3747.

Dye, T. (2013). Understanding public policy (14 ed.). United States: Pearsons Education.

Everett, S. (2003). The policy cycle: democratic process or rational paradigm revisited? Australian Journal of Public Administration, 62(2), pp. 65-70.

Fernández, J. (1999). La expansión de la justicia constitucional en Europa central y oriental. lus et Praxis, 5(2), pp. 321-352.

Fischer, F., Miller, G., y Sidney, M. (2007). Handbook of public policy analysis: theory, politics ands methods. New York, United States of America: CRC Press, Taylor \& Francis Group.

Fix-Zamudio, H. (2002). Breves reflexiones sobre la naturaleza, estructura y funciones de los organismos jurisdiccionales especializados en la resolución de procesos constitucionales. En J. Vega, y E. Corzo (coord.), Tribunales y justicia constitucional (pp. 201-238). Ciudad de México, México: Instituto de Investigaciones Jurídicas UNAM.

Gris, P. y Ramírez, S. (2019). El rol del poder legislativo en la evaluación de políticas públicas. Instituto Belisario Domínguez: notas estratégicas, 55. Recuperado de: http://bibliodigitalibd.senado.gob.mx/bitstream/handle/123456789/4514/NE\%20E valuaci\%c3\%b3n Congreso VF.pdf?sequence=1\&isAllowed=y

Henao, J. (2013). El juez constitucional: un actor de las políticas públicas. Revista de Economía Institucional, 15(9), pp. 67-102.

Hill, M. y Hupe, P. (2002). Implementing public policy: governance in theory and in practice. London, Great Britain: Sage Publications.

Howlett, M. (2019). Moving policy implementation theory foward: a multiple streams/critical juncture approach. Public Policy and Administration, 34(4), pp. 405-430.

Miranda, M. (2018). El tribunal constitucional y el rol del juez constitucional. Lex, 22, pp. 85-100.

Ordoñez, G. (dir.) (2013). Manual de análisis y diseño de políticas públicas. Bogotá, Colombia: Universidad Externado de Colombia.

Organización de las Naciones Unidas. (2020). ¿Qué es el Estado de Derecho? Recuperado de: https://www.un.org/ruleoflaw/es/what-is-the-rule-of-law/

Parsons, W. (2007). Políticas públicas: una introducción a la teoría y la práctica del análisis de políticas públicas. Argentina: Edgar Elgar y Flacso: México.

Quinche, M. y Rivera, J. (2010). El Control Judicial de las Políticas Públicas Como Instrumento de la Inclusión de los Derechos Humanos. Universitas, 121, pp. 113138.

Rossi, P., Freeman, H. y Lipsey, M. (2004). Evaluation a systematic approach (6 ed.). California, United States of America: Sage Publications. 
Stone, D., Maxwell, S., y Keating, M. (2001). Bridging research and policy. United Kingdom: Warwick University. Recuperado de: https://warwick.ac.uk/fac/soc/pais/research/csgr/research/keytopic/other/bridging . $\mathrm{pdf}$

Subroto, A. (2011). Understanding complexities in public policy making process through policy cycle model: a system dynamics approach. Depok, Indonesia: Universitas.

Recuperado

de: https://papers.ssrn.com/sol3/papers.cfm?abstract id=1992756

Tarr, G. A. (2010). Judicial process and jucial policymaking (7 ed.). New York. United States of America: Routledge.

Velásquez, R. (2009). Hacia una nueva definición del concepto "política pública". Desafíos, 20, pp. 149-187.

Anexo de Jurisprudencia

Amparo en Revisión 1359/2015 de la Suprema Corte de Justicia de la Nación de los Estados Unidos Mexicanos. Primera Sala de la Suprema Corte de Justicia de la Nación. (2017). Recuperado de: https://www.scjn.gob.mx/sites/default/files/listas/documento dos/2017-10/AR1359-2015-171025.pdf

Juicio de Amparo 707/2016. (2016). Sentencia del Juzgado Séptimo de Distrito Michoacán. Recuperado de: http://sise.cjf.gob.mx/SVP/word1 .aspx?arch=941/0941000019323546037.doc 1 \&sec=Isela Estefania Bueno Gallegos\&svp=1

Sentencia de la Corte Constitucional de Sudáfrica. (4 de octubre, 2000). Government of the Republic of South Africa. \& Ors v Grootboom \& Ors 2000 (11) BCLR 1169. Recuperado de: https://www.escr-net.org/es/caselaw/2006/government-republicsouth-africa-ors-v-grootboom-ors-2000-11-bclr-1169-cc-esp

Sentencia de la Corte Suprema de Justicia de la Nación Argentina. Del 8 de julio de 2008. M. 1569. XL. Mendoza, Beatriz Silva y otros c/ Estado Nacional y otros s/ daños y perjuicios (daños derivados de la contaminación ambiental del Rio Matanza - Riachuelo). Recuperado de: https://www.escrnet.org/es/caselaw/2011/mendoza-beatriz-silva-y-otros-c-estado-nacional-yotros-s-danos-y-perjuicios-danos 